\title{
Os efeitos de (não) sentido do autismo para o sujeito ideológico*
}

Cynara Maria Andrade Telles**

Resumo: Apresentar do conceito de sujeito ideológico proposto pela Análise do Discurso é o nosso objetivo. Sob esse prisma, concebe-se um sujeito determinado ideologicamente, que enuncia de acordo com a posição social e os lugares que ocupa para empreender seu discurso, legitimando e reproduzindo dizeres autorizados e calando outros. Afetado historicamente, circula por vários lugares, posicionando-se segundo o que e para quem irá produzir seu discurso. Para a Análise do Discurso, teoria e métodos são indissociáveis, e por isso, em nosso corpus de análise, apresentaremos recortes de mães dizendo de seus (não) saberes sobre o autismo.

Palavras-chave: Análise do Discurso; sujeito ideológico; autismo.

\section{Introdução: o conceito de sujeito}

O conceito de sujeito é um dos pilares da teoria da Análise do Discurso, por ser ele o agente que faz voz ao discurso, e assim como o sujeito psicanalítico, é descentrado, não quantificável, definido como posição na linguagem e submetido a ela, ocupando um lugar de anterioridade em que seu dizer engata em dizeres anteriores, marcado por um processo sócio-histórico, não sendo ele a fonte de seu dizer. Isso implica tomar tal noção a partir de uma posição discursiva dada por determinadas condições e que, para flagrar movimentos de sentido em seu discurso, é importante observar a partir de que posição e para quem discursiviza esse sujeito. É preciso escutar o lugar de onde ele fala, num dado momento, levando em conta que este lugar não é fixo, fazendo esse sujeito ir e vir de uma posição a outra. Grigoletto (2005) destaca que o sujeito (afetado pelo inconsciente) tem a ilusão de que é possível efetuar um apagamento do seu lugar social. Entretanto, esse apagamento é somente um efeito, pois sua inscrição num determinado lugar discursivo implica sempre uma determinação do lugar social. Ou seja, sempre haverá uma determinação ideológica. E é especificamente desse sujeito ideológico proposto pela Análise do Discurso de filiação francesa que pretendemos tratar aqui, apontando nos dizeres de mães de filhos autistas seus (não) saberes sobre essa doença, amparando-se nos saberes da ciência para tecerem seus discursos.

\section{A captura ideológica do sujeito discursivo}

Afirmando que o sujeito da ciência é aquele com o qual se opera na linguagem, Lacan está apontando para o fato que é a ciência que define o contexto atual

\footnotetext{
* Esse texto é um recorte da dissertação de mestrado "O(s) obscuro(s) dizer(eres) de mães sobre o autismo de seus filhos" (2011).

** Mestre pelo Programa de Pós-graduação em Ciência, Tecnologia e Sociedade da UFSCar. E-mail: cynaratelles@ig.com.br
} 
em que vivemos, ou seja, o sujeito da atualidade. Este sujeito da ciência e do conhecimento deve ser pensado como um sujeito ideológico, sendo ele o efeito de determinações históricas, políticas e sociais, não entendido aqui como um sujeito com liberdade para se posicionar no espaço social que participa, mas sempre afetado por essas determinações.

Uma importante articulação faz Pêcheux (1995) entre sujeito do inconsciente, sujeito ideológico e sujeito do discurso ao afirmar que o Sujeito, definido como absoluto e universal, se correlaciona ao Outro, tesouro dos significantes, fonte do discurso e advento do inconsciente. Quando falamos em sujeito, temos que pensar sua existência representada na materialidade da língua, no discurso afetado pela ideologia, sendo essa a marca de distinção entre o sujeito lacaniano e o sujeito pecheuxtiano. Ao tratar disso, Pêcheux (1995), afirma que o 'não-sujeito' é interpelado-constituído pela Ideologia. A ideologia, por sua vez, é um mecanismo de naturalização de sentidos que nunca se completa, não sendo, portanto, um conceito rigidamente fechado e estável, e sim, marcado pela contradição, pela tensão, pela disputa, pelo movimento e pela luta de classes, ancorando sentidos no dizer (ROMÃO, 2002).

O sujeito é interpelado a partir da posição ideológica que ocupa num determinado contexto sócio-histórico ao qual está filiado, em que o outro se presentifica por meio de filiações e transferências. Esse posicionamento é um mecanismo imaginário da ideologia, cujo processo de interpelação / identificação promove uma naturalização de sentidos, fazendo com que o sujeito não se dê conta de seu assujeitamento segundo uma determinada posição social que ocupa, dando ainda a ilusão de uma posição clara e objetiva quando enuncia, e de univocidade de seu dizer. Assim, o sujeito esquece que seu dizer já está dado, uma vez que o "funcionamento ideológico apaga no sujeito, o fato de ele entrar em práticas histórico-discursivas já existentes" (MARIANI, 1998), o que promove a organização de Formações Ideológicas, representantes do que seria possível dizer dentro de uma determinada formação social e do lugar social que o sujeito ocupa na sociedade de poder ou não poder dizer, ou ainda, poder dizer de uma forma e não poder dizer de outra, a partir de um processo sócio-histórico já dado. A possibilidade de dizer de um modo ou de outro, segundo a posição ocupada pelo sujeito, é definida por Formação Imaginária. As Formações Ideológicas determinam os discursos a partir do contexto histórico e da posição social ocupada pelo sujeito.

Pêcheux (1995) participa do guarda-chuva da teoria geral das ideologias proposto por Althusser. Em suas contribuições, propõe se pensar o conceito de ideologia na teoria discursiva como o lugar e meio de realização de expressão da ideologia dominante. Representada pelas instituições, tais como Igreja, Governo, Família, Ciência, etc., a ideologia interfere na produção do processo sócio-histórico em que alguns sentidos do discurso são formalizados/valorizados de acordo com as práticas sociais vigentes que se manifestam e se constituem no interior das lutas de classes. Os Aparelhos Ideológicos de Estado constituem "simultânea e contraditoriamente, o lugar e as condições ideológicas da transformação das relações de produção" (PÊCHEUX, 1995, p. 145). A Análise do Discurso não concebe a possibilidade de que todos os Aparelhos Ideológicos de Estado, todas as instituições, se empenhem de forma regular e equilibrada para a transmissão e transformação das relações de produção. As instituições determinam e legitimam práticas discursivas definindo rotas de sentidos e normas de agir. São essas definições que distinguem as formulações de Althusser das de 
Pêcheux sobre ideologia, ou seja, o caráter heterogêneo, irregular e as vetorizações das instituições quanto ao modo de dar sentidos ao discurso, abandonando, portanto, seu caráter homogêneo e estável.

Tratando da articulação entre o materialismo-histórico e a psicanálise, Pêcheux necessariamente se debruça a refletir o sujeito althusseriano do Outro lacaniano. Teixeira (2000) faz a partir dessa articulação uma retomada do percurso de Althusser sobre o sujeito psicanalítico. A autora apoia-se na relação do sujeito com a vertente imaginária, empreendendo suas reflexões a partir do trabalho de Lacan (1998) sobre o estádio do espelho, para estabelecer os postulados do sujeito ideológico. Nesse trabalho, Lacan aponta o momento em que o bebê, apesar de sua condição anterior à possibilidade de representação de seu próprio corpo independente do corpo do Outro, antecipa num júbilo de completude a imagem de si, pelo espelhamento ao outro. Em termos ideológicos, é assim que se procede ao processo de assujeitamento a um discurso dominante, alienando-se imaginariamente a esse discurso.

Althusser não leva em conta a necessidade de um trabalho de investimento posterior ao nascimento do bebê, o que representa a ordem simbólica de constituição do sujeito. Limitando-se à vertente imaginária de constituição do sujeito, Althusser acabou capturado pelo conceito de imaginário, demanda lançada ao Outro - lugar do eu, das ilusões de completude, da alienação, do engodo, e daquilo que participa da formação da imagem do corpo humano. A movimentação do sujeito atual entre seus direitos e deveres leva-o a se filiar em posições discursivas diversas, ocupando por vezes posições ideológicas antagônicas que nem sempre lhe são claras, num momento se opondo ao discurso legitimado de autoridade, mudando para uma posição de filiação a esse mesmo discurso, como veremos no material analisado, em que o sujeito leigo, ao falar do autismo, se posiciona discursivamente em diferentes lugares, afetado pelo processo sócio-histórico no qual está inserido, fazendo-o circular e ressignificando seus sentidos ${ }^{3}$.

\section{(Re)Significando sentidos}

Conforme já adiantamos, a articulação do método à teoria é a proposta a Análise do Discurso em que o analista do discurso empreende um movimento de retorno ao passado discursivo e de volta ao presente, o sujeito entrevistador/pesquisador participa subjetivamente do processo interpretativo. É nessa posição que se empreendeu a composição do corpus de análise, utilizando a escuta de sujeitos em sua subjetividade, dentro de um contexto histórico-ideológico determinado. A constituição do corpus e o trabalho de análise baseiam-se no tratamento de dados discursivos abertos, pois são tomados pela anterioridade e pertencentes a um processo discursivo, à memória e à materialidade linguística.

No recorte que segue, destacamos a estabilidade de um dizer sobre o não entendimento do autismo do filho:

Melissa: 'Aí, foi... eu não sabia o que que era. Tanto é que eu, é igual eu, como fala, a gente... perguntei pras pessoas, ninguém sabe o que é autista, porque é

\footnotetext{
${ }^{3} \mathrm{O}$ material deriva de entrevistas realizadas com mães de filhos autistas, e que compõem o corpus de análise de nosso trabalho de dissertação. Nas transcrições foram mantidos os modos coloquiais de dizeres das mães.
}

fragmentum, N. 32. Laboratório Corpus: UFSM, Jan./ Mar. 2012 
muito pouco divulgado, muito pouco falado, né? Não é como Síndrome de Down... então a partir daí nós começamos a procurá, a estudá livro, internet, procurá, sabe como é, o porquê., Aí começamo a fazê parte de genética, fomo procurá geneticista, tudo, porque que dá aquilo, fazê o X Frágil dele tamém, que ele pediu, né'.

Num primeiro momento o sujeito vacila antes de se posicionar sobre, já o movimento seguinte, diante do diagnóstico, é de buscar por vários meios um entendimento de uma doença pouco conhecida, pouco divulgada, precisando recorrer à internet, livros e geneticistas para tentar entender, busca essa não colocada ou silenciada no discurso anterior. $\mathrm{O}$ sujeito mãe enuncia de uma posição de não saber para a de alguém que pode buscar saber. Verificamos, então, que em termos práticos, a tentativa de objetivação da ciência quanto ao saber sobre o autismo, não se faz por completo, apontando pelo discurso das mães furos e opacidades do dizer da ciência sobre o autismo.

\section{Considerações finais}

Como pudemos ver, o sujeito ideológico em cada tomada de seu discurso, afetado sócio-historicamente, se posiciona de maneira a dizer de seu saber ou não saber, no nosso caso, sobre o autismo. Esse sujeito está constantemente afetado por dizeres anteriormente legitimados. Ele não é aqui pensado como um sujeito livre para dizer o que pretende, visto que para dizer precisa necessariamente recorrer à rede de memórias na qual está socialmente inserido. $\mathrm{O}$ sujeito mãe posiciona-se como sujeito que não sabe o que acontece com seu filho, buscando nos dizeres do saber autorizado da ciência, respostas a essas questões. Seus discursos sobre o autismo apontam um sentido carregado de efeito de doença, e os desdobramentos dessa informação para cada um desses sujeitos, impondo novos modos de significar esse filho após receberem um rótulo, um nome, uma resposta, uma sentença.

\section{Referências}

GRIGOLETTO, S. A noção de sujeito em Pêcheux: uma reflexão acerca do movimento de desidentificação. Estudos da lingua(gem). Vitória da Conquista, n. 1, jun. 2005.

LACAN, J. O estádio do espelho como formador da função do eu. Escritos. Traduzido por Vera Ribeiro. Rio de Janeiro: Jorge Zahar, 1998.

MARIANI, Bethânia. O PCB e a imprensa: os comunistas no imaginário dos jornais (1922-1989). Rio de Janeiro: Revan; Campinas, SP: UNICAMP, 1998.

ORLANDI, E. P. Maio de 1968: os silêncios da memória. In: ACHARD, P. [et.al.]. Papel da memória. Traduzido por J. H. Nunes. Campinas, SP: Pontes, 1999.

PECCHEUX, M. Semântica e discurso: uma crítica à afirmação do óbvio. Traduzido por Eni P. Orlandi. 2. ed. Campinas, SP: Editora da UNICAMP, 1995.

ROMÃO, L. M. S. O litígio discursivo materializado no MST: a ferida aberta na nação. Tese (Doutorado em Psicologia). Faculdade de Filosofia, Ciências e Letras de Ribeirão Preto, Universidade de São Paulo. Ribeirão Preto, SP: USP, 2002. 
TEIXEIRA, M. O atravessamento pela psicanálise. In: FERREIRA, M. C. L. (org.). Análise de discurso e psicanálise: uma estranha intimidade. Porto Alegre, RS: Edipucrs, 2000. 